\title{
Indicators needed to design a student dashboard from lecturers' perspectives: a qualitative study
}

\author{
Iñigo Arriaran Olalde, Nagore Ipiña Larrañaga
}

Mondragon Unibertsitatea, Spain.

\begin{abstract}
The number of students' enrolled in Higher Education online courses is increasing, and as a result, more data about their learning process is generated. The data produced can be displayed on a dashboard and help students in their learning process. However, lecturers' perspective should be taken into account to define the indicators of the dashboard as the design of the courses could impact on the elements included on it. And that is precisely the aim of this paper: to define the indicators needed to design a student dashboard in online courses taking into account lecturers' perspectives. This study was carried out with 10 lecturers from the Faculty of Humanities and Education from Mondragon Unibertsitatea. Online qualitative questionnaires were used to gather participants' perceptions. Results show that most of the lecturers participating in the research study identified four indicators to design a student dashboard: number of times students access the course forum, amount of contributions in the forum, number of times students consult the information booklet, and number of times each student has accessed the course in a week time. Conclusions drawn from this study highlight the importance of training lecturers and students on the pedagogical use of data visualization.
\end{abstract}

Keywords: learning analytics; dashboard; course design; lecturer; student learning process; self-regulation. 


\section{Introduction}

The number students in online courses has increased in the last decade (Ipiña, Basagoiti, Jimenez \& Arriaran, 2016). Therefore, data generated about their learning process in those technology enhanced learning spaces is also growing (Means, 2014). Learning Analytics (LA) arises with the aim of using student activity data in Learning Management Systems (LMS) to increase understanding of the learning experience and better support students (Dawson, Gasevic, Siemens, \& Joksimovic, 2014). In fact, LA uses predictive modelling techniques based on the use of different algorithms to analyse students' digital traces in order to understand and optimize learning processes (Pardo, Jovanovic, Dawson, Gasevic, \& Mirriahi, 2017).

LA research represents a broad array of methods that are used to derive support actions for students (Ferguson, 2012). Possible applications include: improving students' success (Arnold, Hall, Street, Lafayette, \& Pistilli, 2012), better understanding the nature of social learning among university students (Buckingham Shum \& Ferguson, 2012), improving learning design approaches (Mor, Ferguson, \& Wasson, 2015), and guiding university education strategy (Rientes, Boroowa, Cross, Kubiak, Mayles \& Murphy, 2016). The information derived from these applications are presented to lecturers or shown directly to students in the form of different dashboards (Verbert, Govaerts, Duval, Santos, Assche, Parra, et al., 2014), but most of the times with the purpose of supporting students' reflection on their learning process (Krumm, Waddington, Teasley \& Lonn, 2014; Tanes, Arnold, King \& Remnet, 2011).

However, more recent research in the area of LA attempts to understand students' reactions to the data visualized and presented in these dashboards. For example, Corrin and de Barba (2015) found that students were not able to interpret the information provided in the commonly used dashboards and, therefore, the effects on their learning were non-existent and sometimes even negative. Therefore, as some researchers pointed out (Gasevic, Dawson, \& Siemens, 2015; Wise, 2014), there is a need to focus more on how to understand the meaning of the data provided by the dashboards, so that there is a positive influence on the learning scenario. Nonetheless, research conducted on the pedagogical use of data visualization and its impact on students learning process in scarce. And that is precisely the aim of the present paper: to analyze lecturers' perspective on the indicators needed to offer students a dashboard that could positively impact on their learning process.

\section{Dashboard in LMS}

Several terms are currently used as synonyms of "learning dashboards"; e.g., "educational dashboard", "dashboard for learning analytics", "data dashboard", and "web dashboard" (Schwendimann, Rodriguez-Triana, Vozniuk, Prieto, Shirvani Boroujeni, Holzer, Gillet \& 
Dillenbourg, 2016). Yoo, Lee, Jo \& Park (2015) defined a learning dashboards as "a display which visualizes the results of educational data mining in a useful way" (p. 145), while Steiner, Kickmeier-Rust \& Albert (2014) referred to it as "visualization of learning traces" (p. 9), Schwendimann et al. (2016) stated that a learning dashboard "is a single display that aggregates different indicators about learner(s), learning process(es) and/or learning context(s) into one or multiple visualizations” (p. 8). The use of different terms and definitions suggests that there is still no consensus on what constitutes a learning dashboard, and therefore, more studies are needed. However, the big challenge now is to make data from learning platforms processable by analyzing them and presenting them in such ways that are meaningful to different stakeholders (Sutherland, Eagle \& Joubert, 2012).

While the popularity of learning dashboards has been increasing in recent years, the question of what 'correct' information is shown to different stakeholders and how this information should be presented remains largely unresolved. Few (2007) points out that, although visually appealing, many dashboards lack the ability to provide really useful information. Thus, so that dashboards become useful tools in students' learning process, the information should be displayed on dashboards one timely and accurate manner; i.e., should be coherent with the learning design (Baker, 2007).

\section{Learning design}

The learning design describes the sequence of learning tasks, resources, and supports that a lecturer builds for students during part or all of the academic semester (Goodyear, 2015). As such, learning designs provide a model of intentions in a particular learning context that can be used as a framework for the design of analytics to support university students in their learning and university lecturers in their teaching decisions (Lockyer, Heathcote \& Dawson, 2013). Although this overcomes the difficulties of data accuracy, the challenge of learning analysis is to interpret the resulting data according to pedagogical intent and local context to assess the success or otherwise of a particular learning activity (Dawson, Bakharia, Lockyer \& Heathcote, 2010).

Moreover, the interpretation of the visualizations also depends to a great extent on the understanding the context in which the data were collected and the objectives of the lecturer with respect to the interaction class (Leony, Pardo, de la Fuente Valentín, De Castro \& Kloos, 2012). Therefore, interpretation of the analysis requires an alignment with the original teaching context to be useful as feedback on whether the learning design has achieved its purpose. Interpretation requires an understanding of the relationship between technology functionality, observed interaction behaviors, and educational theory (Heathcote, 2006). It is the conceptual bridge and understanding between the technical and educational context that remains problematic for learning analytics (Dawson, Heathcote \& Poole, 2010). 


\section{Research}

\subsection{Aim}

The objective of this paper is to define the indicators needed to design a student dashboard for online courses taking into account lecturers' perspectives.

\subsection{Context and sample}

The present study was carried out in Mondragon Unibertsitatea (MU henceforth). The study was conducted in the Faculty of Humanities and Education, where Primary Education Degree and Early-Years Education Degree are offered in the online modality. 10 lecturers involved in 10 different online courses participated in the study.

\subsection{Instruments and procedure followed}

Online qualitative questionnaires were used in this study. The open-question questionnaire was designed following the framework proposed by Pardo et al. (2017) and aimed at understanding the perceptions lecturers have about the most suitable indicators to be included in the student dashboard. All lecturers were given 5 days to fill in the questionnaire. A content analysis was conducted with the Atlas.ti software for qualitative analysis. Results obtained are depicted in the next section.

\section{Results}

All participants taking part in the study considered that using a dashboard to visualize students' progress and data could be important for students' learning process. In fact, $75 \%$ of the lecturers recognized that visualizing data is a key aspect to promote self-regulation and reflection about students' learning process. Moreover, participants of the research study asserted that data should be visualized at the beginning of the learning process as well as during and after the course. In the same line, all lecturers stated that they would be very interested in knowing how students use the educational resources offered in their courses. Furthermore, results indicated that data provided in the student dashboard may guide the redesign of the online courses included the resources offered in the platform. Nonetheless, $90 \%$ of the lecturers participating in the study state that training on the pedagogical use of data visualization is needed before using the student dashboard.

A summary of the indicators found is depicted in Table 1. Overall, four are the main indicators identified by the participants to design a student dashboard: number of times students access the course forum, amount of contributions in the forum, number of times students consult the information booklet, and number of times each student has accessed the course in a week time. 
Table 1. Indicators chosen by the participants to design a student dashboard for online courses

\begin{tabular}{cc}
\hline Indicator & \% of lecturers \\
\hline No. of times students access the course forum & $100 \%$ \\
Amount of contributions in the forum & $100 \%$ \\
No. of times students consult the information booklet & $80 \%$ \\
No. of times each student has accessed the course in a week time & $60 \%$ \\
No. of tasks delivered out of date & $40 \%$ \\
Satisfaction questionnaire filled in & $20 \%$ \\
(tracking) & $20 \%$ \\
\hline
\end{tabular}

Source: The Author/s (2019).

\section{Conclusions and further research}

Results have shown that the participants of the study highly valued the importance of visualizing educational data to foster students' learning process in a meaningful way. Likewise, as Leony et al. (2012) and Pardo et al. (2017) claimed, visualizing data is perceived as very useful for student self-regulation and reflection within the learning context. Beside, our findings are aligned with the results found by Krum et al. (2014) and Tanes et al. (2011) as lecturers stated that they would be very interested in knowing how students use their course resources. Moreover, participants considered that these data could help in the redesign of their courses (Lockyer et al., 2013). Furthermore, 90\% of the lecturers participating in the study state that training on the pedagogical use of data visualization is needed before using the student dashboard as stated by Schwendimann et al. (2016).

Lecturers considered that four indicators are most interesting to design a student dashboard: number of times students access the course forum, amount of contributions in the forum, number of times students consult the information booklet, and number of times each student has accessed the course in a week time. The indicators found could guide our next approach; however, future research should analyze the impact of using dashboard on students learning process. Nonetheless, students' perception towards the use of dashboards for educational purposes needs further studies. Moreover, further research is required to gain a deeper insight of the impact the online courses design can have on definition of indicators to design a student dashboard. 


\section{References}

Arnold, K. E., Hall, Y., Street, S. G., Lafayette, W., \& Pistilli, M.D. (2012). Course signals at Purdue: Using learning analytics to increase student success. In S. Buckingham Shum, D. Gasevic, \& R. Ferguson (Eds.), International Conference on Learning Analytics and Knowledge (pp. 267-270). New York, NY: ACM Press.

Baker, B. M. (2007). A conceptual framework for making knowledge actionable through capital formation. University of Maryland University College.

Buckingham Shum, S., \& Ferguson, R. (2012). Social learning analytics. Educational Technology \& Society, 15(3), 3-26.

Corrin, L., \& de Barba, P. (2015). How do students interpret feedback delivered via dashboard? Paper presented at the International Conference on Learning Analytics and Knowledge, Poughkeepsie, NY.

Dawson, S., Gasevic, D., Siemens, G., \& Joksimovic, S. (2014). Current state and future trends: a citation network analysis of the learning analytics field. Paper presented at the International Conference on Learning Analytics and Knowledge, Indianapolis, IN.

Dawson, S., Bakharia, A., \& Heathcote, E. (2010). SNAPP: Realising the affordances of realtime SNA within networked learning environments. Networked Learning-Seventh International Conference.

Dawson, S., Heathcote, E., \& Poole, G. (2010). Harnessing ICT potential: The adoption and analysis of ICT systems for enhancing the student learning experience. International Journal of Educational Management, 24(2), 116-128.

Ferguson, R. (2012). The state of learning analytics in 2012: a review and future challenges (KMI-12-01). The Open University, UK.

Few, S. (2007). Dashboard confusion revisited. Perceptual Edge.

Gasevic, D., Dawson, S., \& Siemens, G. (2015). Let's not forget: learning analytics are about learning. TechTrends, 59, 64-75.

Goodyear, P. (2015). Teaching as design. HERDSA Review of Higher Education Vol. 2, (pp. 27-50).

Heathcote, E. (2006). Learning design templates-A pedagogical just-in-time support tool. In G. Minshull \& J. Mole (Eds.), Designing for learning: The proceedings of Theme 1 of the JISC Online Conference: Innovating e-Learning (pp. 19-26).

Ipiña, N., Basagoiti, R., Jimenez, O., \& Arriaran, I. (2016). Recommendations as a key aspect for online learning personalization: perceptions of teachers and students. International Scholarly and Scientific Research \& Innovation 10(10) 3391-3395. doi:10.5281/zenodo.1127511

Krumm, A. E., Waddington, R. J., Teasley, S. D., \& Lonn, S. (2014). A learning management system-based early warning system for academic advising in undergraduate engineering. In J. A. Larusson \& B. White (Eds.), Learning analytics: from research to practice (pp. 103-119). New York: Springer Science+Business Media.

Leony, D., Pardo, A., de la Fuente Valentín, L., De Castro, D. S., \& Kloos, C. D. (2012). GLASS: A learning analytics visualization tool. 2nd International Conference on Learning Analytics and Knowledge. 
Lockyer, L., Heathcote, E., \& Dawson, S. (2013). Informing pedagogical action: Aligning learning analytics with learning design. American Behavioral Scientist 57 (10) 14391459.

Means, B. (2014). Learning Online. What research tells us about whether, when and how. New York: Routledge.

Mor, Y., Ferguson, R., \& Wasson, B. (2015). Editorial: Learning design, teacher inquiry into student learning and learning analytics: A Call for action. British Journal of Educational Technology, 46(2), 221-229.

Pardo, A., Jovanovic, J., Dawson, S., Gasevic, D., \& Mirriahi, N. (2017). Using learning analytics to scale the provision of personalised feedback. British Journal of Educational Technology. doi: 10.1111/bjet.12592.

Rientes, B., Boroowa, A., Cross, S., Kubiak, C., Mayles, K., \& Murphy, S. (2016). Analytics4Action evaluation framework: A review of evidence-based learning analytics interventions at the Open University UK. Journal of Interactive Media in Education, 1(2), 1-11. doi:10.5334/jime.394

Schwendimann, A., Rodriguez-Triana, M. J., Vozniuk, A., Prieto, L. P., Shirvani Boroujeni, M., Holzer, A., Gillet, D., Dillenbourg, P. (2016). Perceiving learning at a glance: A systematic literature review of learning dashboard research. IEEE Transactions on Learning Technologies 10(1), 1-1. doi:10.1109/TLT.2016.2599522

Steiner, C. M., Kickmeier-Rust, M. D., \& Albert, D. (2014). Learning analytics and educational data mining: An overview of recent techniques. Learning analytics for and in serious games, pp. 6-15.

Sutherland, R., Eagle, S., \& Jobert, M. (2012). A vision and strategy for Technology Enhanced Learning. STELLAR Network of Excellence.

Tanes, Z., Arnold, K. E., King, A. S., \& Remnet, M. A. (2011). Using signals for appropiate feedback: perceptions and practices. Computers \& Education, 57, 2414-2422. doi:10.1016/j.compedu.2011.05.016

Verbert, K., Govaerts, S., Duval, E., Santos, J.L., Assche, F., Parra, G., et al. (2014). Learning dashboards: an overview and future research opportunities. Personal and Ubiquitous Computing, 18 1499-1514. doi:10.1007/s00779-013-0751-2

Wise, A. F. (2014). Designing pedagogical interventions to support student use of learning analytics. Paper presented at the International Conference on Learning Analytics and Knowledge, New York, NY.

Yoo, Y., Lee, H., Jo, I. H., \& Park, Y. (2015). Educational dashboards for smart learning: Review of case studies. Emerging Issues in Smart Learning. Springer, (pp. 145-155). 